Article

\title{
The Sentinel-1 Mission: New Opportunities for Ice Sheet Observations
}

\section{Thomas Nagler ${ }^{1, *}$, Helmut Rott ${ }^{1,2}$, Markus Hetzenecker ${ }^{1}$, Jan Wuite ${ }^{1}$ and Pierre Potin ${ }^{3}$}

1 ENVEO IT GmbH, Technikerstrasse 21a, A-6020 Innsbruck, Austria;

E-Mails: Helmut.Rott@enveo.at (H.R.); Markus.Hetzenecker@enveo.at (M.H.); Jan.Wuite@enveo.at (J.W.)

2 Institute for Meteorology and Geophysics, University of Innsbruck, A-6020 Innsbruck, Austria

3 European Space Agency/ESRIN, via Galileo Galilei, I-00044 Frascati, Italy;

E-Mail: Pierre.Potin@esa.int

* Author to whom correspondence should be addressed; E-Mail: Thomas.Nagler@enveo.at; Tel.: +43-512-507-48300; Fax: +43-512-507-48319.

Academic Editors: Nicolas Baghdadi and Prasad S. Thenkabail

Received: 28 May 2015 / Accepted: 14 July 2015 / Published: 22 July 2015

\begin{abstract}
The Sentinel satellite constellation series, developed by the European Space Agency, represents the dedicated space component of the European Copernicus program, committed to long-term operational services in a wide range of application domains. Here, we address the potential of the Sentinel-1 mission for mapping and monitoring the surface velocity of glaciers and ice sheets. We present an ice velocity map of Greenland, derived from synthetic aperture radar (SAR) data acquired in winter 2015 by Sentinel-1A, the first satellite of the Copernicus program in orbit. The map is assembled from about 900 SAR scenes acquired in Interferometric Wide swath (IW) mode, applying the offset tracking technique. We discuss special features of IW mode data, describe the procedures for producing ice velocity maps, and assess the uncertainty of the ice motion product. We compare the Sentinel-1 ice motion product with velocity maps derived from high resolution SAR data of the TerraSAR-X mission and from PALSAR data. Beyond supporting operational services, the Sentinel-1 mission offers enhanced capabilities for comprehensive and long-term observation of key climate variables, such as the motion of ice masses.
\end{abstract}

Keywords: Sentinel-1; SAR; ice motion; Greenland 


\section{Introduction}

The Sentinel satellite constellation series, developed by the European Space Agency (ESA), represents the dedicated space component of the European Copernicus program (formerly called Global Monitoring for Environmental Security, GMES) [1]. Copernicus, led by the European Union, is an ambitious operational Earth Observation program providing global, timely and easily accessible information in application domains such as land, marine, atmosphere, emergency response, climate change, and security. The Copernicus program comprises three components, namely the space component, the in-situ component, and the service component. Though the main mandate of the Copernicus space component is the support of operational services, the improved observational capabilities and the long-term operational commitment of the Sentinel missions will also provide the science community with unique and comprehensive observations on the various components of the Earth System $[2,3]$.

Here, we address the potential of the Sentinel-1 mission for mapping and monitoring the surface velocity of glaciers and ice sheets, presenting the first ice sheet wide velocity map for Greenland derived from Sentinel-1 synthetic aperture radar (SAR) data acquired between January and March 2015. The Sentinel-1 mission is based on a constellation of two satellites equipped with a C-band SAR sensor. Sentinel-1A, launched on 3 April 2014, is the first dedicated satellite of the Copernicus program in orbit [4]. The launch of the second Sentinel-1 satellite, Sentinel-1B, is scheduled for early 2016. The repeat cycle of a single satellite is 12 days, dropping to 6-day repeat orbit for the two-satellite constellation. The Sentinel-1 SAR instrument, with its active phased array antenna, supports four different operational imaging modes that are providing different resolution and coverage: Interferometric Wide swath (IW) mode, Extra Wide swath (EW) mode, Strip-Map (SM) mode, and Wave (WV) mode [5,6]. The mode is either optimized for spatial resolution or for swath width. The Greenland ice velocity map is based on data of the IW mode, which is the nominal mode for land areas, including ice sheets [4]. In order to check the performance of the velocity maps derived from IW data, we compare the Sentinel-1 products with velocity maps derived from very high-resolution SAR data of the TerraSAR-X mission acquired over several outlet glaciers.

Satellite observations and in situ measurements reveal a high temporal variability of ice flow for outlet glaciers of ice sheets over time scales ranging from days to years [7-10]. Therefore comprehensive, detailed and long-term observations on the temporal and spatial patterns of ice flow are needed to better understand and quantify the processes that are governing the response of ice sheets to climate forcing and to improve estimates on future ice sheet contributions to sea level rise. Moon et al. [11] used SAR data to produce velocity maps of the main outlet glaciers of the Greenland Ice Sheet for winter 2000 to 2001 and for each winter from 2005 to 2006 through 2010 to 2011, revealing complex spatial and temporal velocity patterns. For the 3rd International Polar Year (IPY) 2007-2009 ice sheet wide maps on surface velocity were generated for Antarctica [12] and Greenland [13]. These maps were assembled from SAR data of several satellite missions: for the Antarctic Ice Sheet from data of PALSAR on the Japanese Advanced Land Observing Satellite (ALOS), of the Canadian RADARSAT-1 and RADARSAT-2 missions, and of the ESA satellites ERS-1, ERS-2, and Envisat [12], for Greenland from data of the Advanced Synthetic-Aperture Radar (ASAR) on Envisat, of ALOS-PALSAR, and of RADARSAT-1 [13]. The Sentinel-1 mission ensures the continuity of C-band SAR data provision by 
ESA, following up the SAR sensors operating on ERS-1, ERS-2, and Envisat, with significantly enhanced capabilities in terms of duty cycle and coverage [4].

\section{Data Sources}

The ice motion map of the Greenland Ice Sheet (Figure 1) has been assembled from 819 Sentinel-1 (S1) SAR scenes in Interferometric Wide swath (IW) mode. The majority of data was acquired during the period January to March 2015. A few tracks were recorded during October to December 2014 and April to June 2015 in order to fill some gaps on the west and southeast coasts. For retrieval of ice motion S1 SAR images of consecutive passes are used, spanning time intervals of 12 and 24 days. In order to check the impact of spatial resolution, we compare S1 ice motion with ice motion maps generated from 11-day repeat pass SAR images of the TerraSAR-X satellite, acquired in strip-map (SM) mode over several outlet glaciers on Greenland's west coast and with 46-day repeat pass ALOS Phased Array-type L-band SAR (PALSAR) images acquired in Fine Beam Single polarization (FBS) mode. Characteristics of the SAR data used for the study are listed in Table 1.

The S1 IW mode is operated as TOPS (Terrain Observation with Progressive Scans in azimuth) mode in order to provide a large swath width of $250 \mathrm{~km}$ at a nominal ground resolution of $5 \mathrm{~m} \times 20 \mathrm{~m}$ for single look data, offering enhanced image performance compared to the conventional ScanSAR mode $[6,14]$. In TOPS SAR imaging mode, the antenna azimuth beam is steered from aft to the fore at a constant rate. As a result, the targets on ground are observed by the entire useful part of the azimuth antenna pattern $[14,15]$. This reduces the scalloping effect significantly and leads to constant azimuth ambiguities and signal-to-noise ratio (SNR) along azimuth. On the other hand, the TOPS mode imposes particular challenges regarding accurate co-registration of image pairs and interferometric processing.

For producing the Greenland ice motion map, we use Sentinel-1 IW Level 1 single look complex (SLC) products. The data set for generating the ice motion map (Figure 1) comprises 28 different tracks and a total data volume of 3 TByte in compressed form. Each image swath in IW mode is composed of three sub-swaths. Individual swaths are subdivided into slices (frames) of about $350 \mathrm{~km}$ length along tracks. Each sub-swath consists of a series of bursts, where each burst is processed as a separate SLC image. For the ice motion map we processed a total of about 28,000 bursts. Most of the swaths over Greenland were acquired at dual polarization (HH and HV). For ice motion retrieval, we use the $\mathrm{HH}$ channel, which has higher signal-to-noise ratio and provides better quality of amplitude features than the HV channel.

The S1 SLC products are focused SAR data preserving the phase information, processed in zero-Doppler/slant-range geometry and geo-referenced using orbit and attitude data from the satellite. The individually focused complex burst images are put into a single sub-swath image in azimuth-time order [16]. The imaged ground areas of adjacent bursts (with a nominal duration of $2.75 \mathrm{~s}$ each) marginally overlap in azimuth, so that contiguous coverage of the ground is achieved. Images for all bursts in all sub-swaths of an IW SLC product are re-sampled to a common pixel spacing grid in range and azimuth. Burst synchronization is ensured, based on a requirement for achieving a synchronization of less than $5 \mathrm{~ms}$ between corresponding bursts. This is essential for interferometric processing of burst mode data and is also relevant for accurate retrievals of surface motion applying offset tracking techniques [17]. 


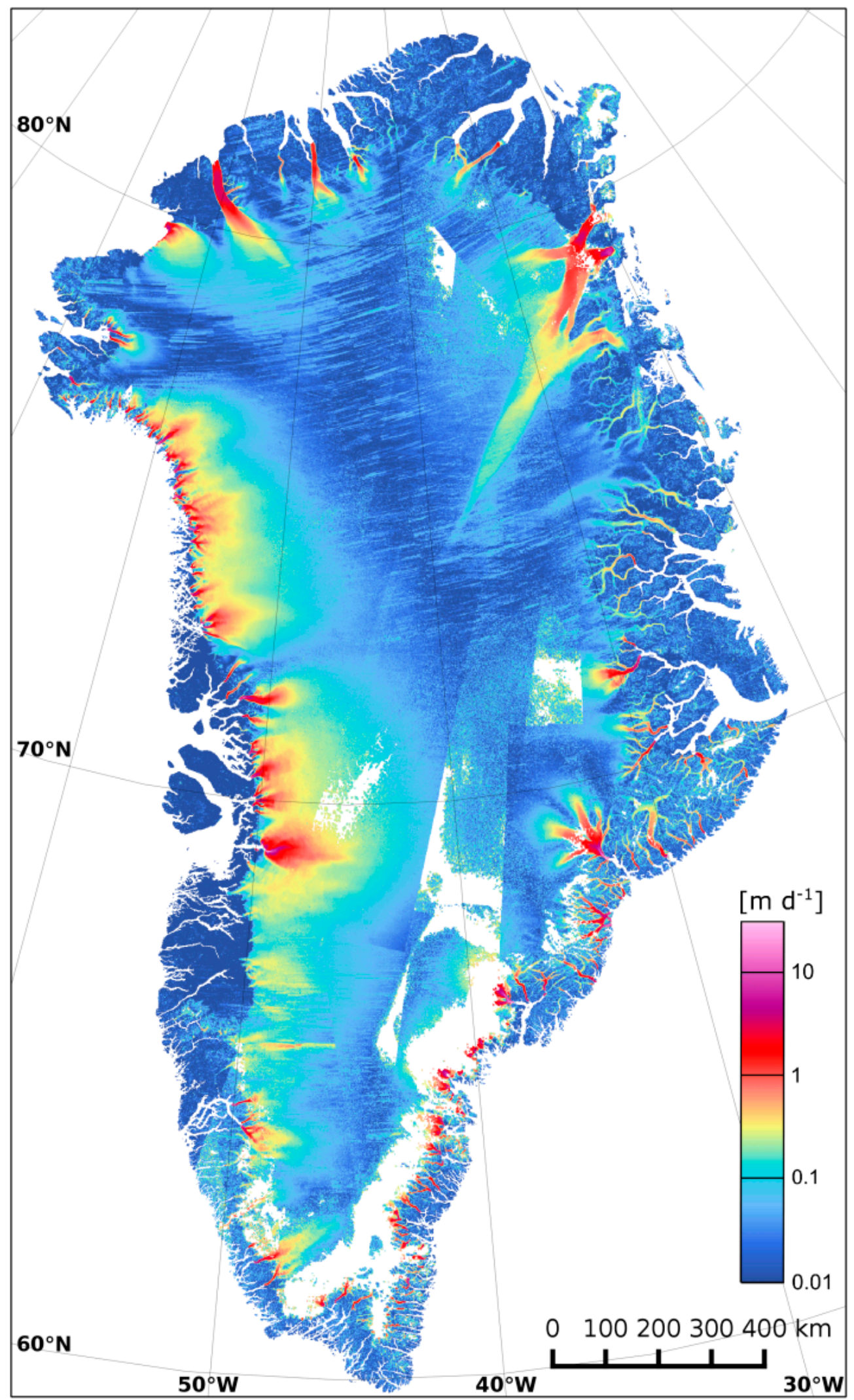

Figure 1. Ice velocity map (magnitude, in logarithmic scale) of the Greenland Ice Sheet derived from SAR data of the Sentinel-1A satellite, acquired in Interferometric Wide Swath Mode (IW) between January and March 2015. 
Table 1. Characteristics of the SAR data used in this study. Pixel spacing refers to single look complex (SLC) data as used for velocity retrievals. Nominal spatial resolution specified for single look data. Gr: Ground range; Az: azimuth; LOS: line-of sight. * includes angles for different tracks.

\begin{tabular}{cccccccc}
\hline Satellite & $\begin{array}{c}\text { SAR } \\
\text { Frequency } \\
(\mathbf{G H z})\end{array}$ & $\begin{array}{c}\text { Repeat } \\
\text { Cycle (Day) }\end{array}$ & $\begin{array}{c}\text { Imaging } \\
\text { Mode }\end{array}$ & $\begin{array}{c}\text { Swath } \\
\mathbf{( k m )}\end{array}$ & $\begin{array}{c}\text { Incidence } \\
\text { Angle (deg) }\end{array}$ & $\begin{array}{c}\text { Nominal } \\
\text { Resolution } \\
\mathbf{G r} \times \mathbf{A z}(\mathbf{m})\end{array}$ & $\begin{array}{c}\text { Pixel Spacing } \\
\mathbf{L O S} \times \mathbf{A z}(\mathbf{m})\end{array}$ \\
\hline Sentinel-1 & 5.4 & 12 & IW & 250 & $30-42$ & $5 \times 20$ & $2.4 \times 13.9$ \\
TerraSAR-X & 9.6 & 11 & SM & 30 & $28-42 *$ & $2 \times 3.3$ & $0.9 \times 1.95$ \\
ALOS & 1.27 & 46 & FBS & 70 & 34 & $7 \times 5$ & $4.7 \times 3.6$ \\
\hline
\end{tabular}

We retrieved velocity maps of the terminus of several outlet glaciers from TerraSAR-X single-look slant-range complex (SSC) images in strip map mode (SM), HH polarization. The SM images extend over a swath width of 30 kilometers. The data over the various sites were acquired from different satellite tracks, with incidence angles, $\theta$, ranging from 28 to 42 degrees depending on the track. The spatial resolution of this product, with $150 \mathrm{MHz}$ chirp bandwidth, is 3.3 meters in azimuth and $2.0 \mathrm{~m}$ in ground range (at $\theta=36^{\circ}$ ) [18], and the pixel size is $0.90 \mathrm{~m} \times 1.95 \mathrm{~m}$ (slant range $\times$ azimuth).

Along the central section of the west coast, we derived ice velocities from 46-day repeat pass data of ALOS PALSAR acquired in FBS mode, spanning the periods 15 September to 31 October 2008 and 20 November 2009 to 5 January 2010. The FBS mode data have a swath width of about $70 \mathrm{~km}$. The $28 \mathrm{MHz}$ chirp bandwidth results in a ground range resolution of about $7 \mathrm{~m}$ at $\theta=34^{\circ}$. The nominal azimuth resolution is $5 \mathrm{~m}$ [19].

\section{Methods}

We apply the offset tracking technique on SAR image pairs of repeat pass orbits to derive surface displacements [20], using an in-house developed software system. The offset tracking technique is less sensitive to temporal stability of the target phase (coherence) than the interferometric SAR method (InSAR) [21]. We checked the interferometric coherence for the 12-day repeat pass S1 SAR image pairs. Snowfall and redistribution of surface snow due to wind are the main causes for temporal decorrelation during winter. The coherence in the S1 data set varies significantly between individual repeat tracks. Along the ice sheet margins and the southern section of the ice sheet, coherence is rather low. Further restrictions for the application of InSAR arise from ambiguities in zones of strong velocity gradients such as the margins of fast flowing ice streams due to the failure in resolving individual phase cycles. The feasibility for resolving velocity gradients depends on the radar signal bandwidth in slant range and on the interferometric time span [22]. For S1 IW mode data phase ambiguities in shear zones prohibit the application of InSAR on fast-flowing outlet glaciers.

Whereas InSAR provides the displacement only in slant range (radar line-of-sight, LOS), offset tracking delivers the components of the surface displacement vector along the flight track (azimuth) and in LOS. The two-dimensional displacement vector in radar imaging geometry is projected onto the surface defined by a digital elevation model (DEM). The resulting surface displacement vector in map projection is defined by two horizontal components (easting, northing) and the vertical component. The vertical component results from the elevation difference between the start position and end position 
of the LOS and azimuth displacement vector projected onto the DEM. We use data of the Greenland Ice Mapping Project (GIMP) digital elevation model (DEM) posted at a $30 \mathrm{~m}$ grid [23]. For generating the S1 Greenland-wide velocity map (Figure 1) we resample the DEM to a $250 \mathrm{~m}$ grid applying bi-linear interpolation. If a pixel is covered by multiple swaths, averaging is performed at pixel scale. The S1, TerraSAR-X and PALSAR velocity data sets used for comparisons on sub-sections of the west coast are posted at a $30 \mathrm{~m}$ grid, using the $30 \mathrm{~m}$ grid of the DEM for geocoding.

Because of different spatial resolutions we perform the cross-correlation with the different SAR products on templates (windows) of different size to calculate two-dimensional offsets (Table 2). The selected window sizes are based on the outcome of performance tests on various outlet glaciers, taking into account signal correlation and the feasibility of resolving gradients in velocity. For Sentinel-1 the rectangular shape of the matching window accounts for the different spatial resolutions in LOS and azimuth. Our matching algorithm applies an iterative approach, where after coarse shift estimation at pixel scale the matching windows are realigned before retrieving the shifts at sub-pixel scale. The sub-pixel shift is calculated by oversampling and interpolating the peak of the cross correlation matrix. The pixel spacing of the final products is $250 \mathrm{~m}$ for the ice sheet wide velocity map of $\mathrm{S} 1$, and $30 \mathrm{~m}$ for the regional velocity maps.

Table 2. Specifications for window size and sampling steps in offset tracking, and for grid size of velocity products. (* ice sheet wide product, ${ }^{\#}$ for comparison with other products).

\begin{tabular}{cccc}
\hline & Sentinel-1 IW & TerraSAR-X & ALOS PALSAR \\
\hline $\begin{array}{c}\text { Matching window size } \\
\text { Pixels (LOS } \times \text { azimuth) }\end{array}$ & $144 \times 48$ & $72 \times 72$ & $144 \times 144$ \\
\hline $\begin{array}{c}\text { Sampling steps } \\
\text { Pixels (LOS } \times \text { azimuth) }\end{array}$ & $40 \times 20$ & $20 \times 20$ & $32 \times 32$ \\
\hline $\begin{array}{c}\text { Velocity product, } \\
\text { Grid spacing in meters } \\
\text { (Easting } \times \text { Northing) }\end{array}$ & $\begin{array}{c}250 \times 250^{*} \\
30 \times 30^{*}\end{array}$ & $30 \times 30$ & $30 \times 30$ \\
\hline
\end{tabular}

Because of the special features and novelty of the S1 IW data, we provide below further information on specific procedures applied for ice velocity mapping. Precise co-registration is performed for the image pairs used for offset tracking. TOPS mode data require high accuracy for image co-registration. A small co-registration error in azimuth can introduce an azimuth phase ramp because of the azimuth variation of the Doppler centroid within the bursts. A local mismatch of the effective velocity of the radar with respect to squint and topography causes positioning errors in azimuth and range [15]. Therefore, we apply geometric co-registration, which makes use of precise orbit data and a DEM for referring the position of each pixel in repeat pass acquisitions to a pre-selected master image [24]. The refinement of the azimuth shifts by using incoherent cross correlation and enhanced spectral diversity, which is optionally applied to TOPS mode interferometry in stationary areas [25], is not applicable on moving ice masses and is not required because of the high accuracy of S1 satellite tracking.

Precise orbit data (ephemerides) are routinely provided for the Sentinel satellites, making use of the Global Navigation Satellite System (GNSS) receiver data on-board. The evaluation of geolocation accuracy using precise orbit data, evaluated over a dedicated site, reveals for SLC data a slant range 
offset of $1.27 \pm 0.06 \mathrm{~m}$ and an azimuth offset of $1.96 \pm 0.41 \mathrm{~m}$ [26]. Because of the high geolocation accuracy with the available orbit data of S1 there is no need for using ground control points for co-registering repeat-pass image pairs. This enables precise co-registration on moving surfaces where ground control points cannot be used. It overrides the need for coast-to coast tracks for improving orbit estimates over ice sheets and the use of balance velocity estimates for ridges and ice divides as applied for adjusting the velocities retrieved from data of previous SAR missions [27,28].

Offset tracking is performed on burst level in slant range (LOS) geometry. The SLC data are oversampled by a factor of two prior to compiling the amplitude image in order to avoid aliasing. The output of the matching procedure consists of three components: the displacements in LOS and in azimuth, and the correlation coefficient. The data of the individual bursts of a track are debursted using the start azimuth time of each burst in order to form a single strip. Subsequently noise reduction is performed in three steps: (i) excluding matches with low correlation; (ii) applying spatial filtering over moving windows of $5 \times 5$ pixels to exclude outliers based on local variance; and (iii) filling small gaps at the scale of individual pixels by interpolation from surrounding displacement values. Displacement images of the individual tracks are projected onto the surface defined by the DEM and averaging is performed for those pixels that are covered by multiple tracks in order to generate the ice sheet wide velocity map.

\section{Results}

\subsection{Sentinel-1 Ice Velocity Map}

The S1 map of the surface velocity is displayed in north polar stereographic projection centered on Greenland, with an origin at $90^{\circ} \mathrm{N}, 45^{\circ} \mathrm{W}$, a standard parallel of $70^{\circ} \mathrm{N}$, and a reference to the WGS84 ellipsoid, corresponding to the projection used for the GIMP DEM [23]. Figure 1 shows the magnitude of the horizontal surface velocity. The velocity mosaic provides near complete coverage of the ice sheet areas west of the main ice divide. Some gaps exist in the interior eastern and southeastern sections of the ice sheet. The terminus sections of all outlet glaciers are covered. Whereas on outlet glaciers the matching signal for offset tracking is based primarily on amplitude features related to surface structure and roughness, distinct amplitude features are sparse in the interior of the ice sheet and stable speckle patterns are required for correlation of image chips. Preservation of speckle requires temporal coherence. In areas exposed to high snowfall and strong winds the temporal decorrelation of the phase signal limits the availability of suitable repeat pass pairs. Most of the gaps in the January to March, 2015 data set could be filled with additional S1 data acquisition during the following months.

On some tracks, in particular in the northern section, stripes are evident being aligned approximately perpendicular to the satellite flight direction. These patterns are due to azimuth shifts induced by fluctuations in ionospheric electron density [29]. The ionosphere-induced noise is mainly of relevance for slow motion areas. It can be efficiently reduced by merging velocity data of multiple tracks.

In order to illustrate and discuss particular features of the Sentinel-1 ice velocity product, we present detailed S1 velocity maps over some of the fast outlet glaciers in the following subsection and compare these with velocity maps derived from TerraSAR-X and PALSAR data. 


\subsection{Comparison with Ice Motion from TerraSAR-X and PALSAR Data}

Maps of ice velocity on the outlet glaciers on the central section of Greenland's west coast are shown in Figure 2, derived from SAR data of S1, TerraSAR-X and ALOS PALSAR. The S1 velocity maps are based on repeat pass data pairs of the time spans 22 December 2014-3 January 2015 and 3-15 January 2015, separated up to one month from the TerraSAR-X images. The TerraSAR-X velocity maps are derived from 11-day, respectively, 22-day, repeat pass pairs of single scenes, each of which covers about $30 \mathrm{~km} \times 50 \mathrm{~km}$ in area. The PALSAR velocity map is based on repeat pass data of a single track, spanning the time period from 20 November 2009 to 5 January 2010. Whereas S1 in IW mode covers the displayed (and actually a much wider) area within a single track, PALSAR in FBS mode covers a strip of about $70 \mathrm{~km}$ width which in this case happens to include the terminus sections of the outlet glaciers. The TerraSAR-X scenes cover limited sections of individual glaciers.

The wider spatial coverage of S1 IW mode accounts for the lower spatial resolution in azimuth compared to strip map mode data of PALSAR and TerraSAR-X. Spatial resolution is of concern for velocity retrievals on fast flowing outlet glaciers. The enlarged sections of S1 and TerraSAR-X amplitude images of two outlet glaciers (Figure 3) show obvious differences in detail of surface features between the two sensors. In order to examine the impact of spatial resolution on velocity retrieval, we show enlarged S1 and TerraSAR-X velocity maps on two sub-areas: four outlet glaciers draining into the northern Disko Bugt (Figure 4), and the lower terminus of Jakobshavn Isbrae (Figure 5). The spatial resolution of TerraSAR-X is 2.5 times higher in ground range and six times higher in azimuth (Table 1). Nevertheless, on the main sections of the Disko Bugt glaciers the motion fields from the two sensors are of similar quality (Figure 4). Some differences are evident on narrow strips along the glacier margins where S1 tends to flatten the velocity gradients.

Whereas the maximum velocity on the outlet glaciers in Figure 4 ranges from $5 \mathrm{~m} \cdot \mathrm{d}^{-1}$ to $15 \mathrm{~m} \cdot \mathrm{d}^{-1}$, the velocity on Jakobshavn Isbrae rises up to $30 \mathrm{~m} \cdot \mathrm{d}^{-1}$ near the calving front. The fast flowing section of the ice stream is only $8 \mathrm{~km}$ wide, resulting in strong velocity gradients across. The offset tracking analysis with S1 IW data fails to provide reliable correlation results for the ice stream section where the central flowline velocity is $>c a .12 \mathrm{~m} \cdot \mathrm{d}^{-1}$ (flagged out in Figure 5). A similar cut-off velocity is observed for PALSAR retrievals. The PALSAR FBS data have higher spatial resolution than S1 IW, so that smaller matching windows can be used. However, this advantage for velocity retrieval in areas of strong gradients is reduced by the longer time interval for acquisition of repeat-pass data.

Figure 6 shows the velocities along the central flowlines on the lower terminus of four outlet glaciers (location in Figure 2), derived from S1, TerraSAR-X and ALOS PALSAR data. Information on the location of the glaciers and on the time span for velocity retrievals is listed in Table 3 . Seasonal and interannual variations in ice velocities have been reported for many marine terminating outlet glaciers of Greenland [11,13,27,30-32]. Here we want to compare the feasibility of the different SAR sensors for tracing ice velocities along the terminal sections of outlet glaciers. Regular observations of velocities on the terminus of outlet glaciers are crucial for quantifying the impact of ice dynamics on mass losses of the Greenland Ice Sheet.

The velocity profiles in Figure 6 are from the cold season when short term fluctuations in velocity are modest compared to the melting period. On each of the four glaciers the ice flow speeds up towards the calving front, a typical pattern for Greenland's marine terminating outlet glaciers [13,27]. For three of 
the glaciers, the S1 analysis provides velocities all along the terminus. For Jakobshavn Isbrae S1 and PALSAR are not able to track the motion down to the front because of the sharp velocity gradients across the ice stream.

The S1 and TerraSAR-X velocity profiles shown in Figure 6 are separated in time up to one month. On Umiammaku Isbrae, Sermeq Silarleq and Store Gletsjer the S1 and TerraSAR-X velocity profiles show close agreement, indicating, on the one hand, comparatively stable velocities during December 2014 and January 2015, and, on the other hand, similar performance of the two sensors for tracking velocities along the central flowlines. Regarding long-term trends, Sermeq Silarleq and Jakboshavn Isbrae show significant acceleration. For Jakobshavn Isbrae, this trend is well documented, as well as the strong seasonal variations of velocity [30,32].

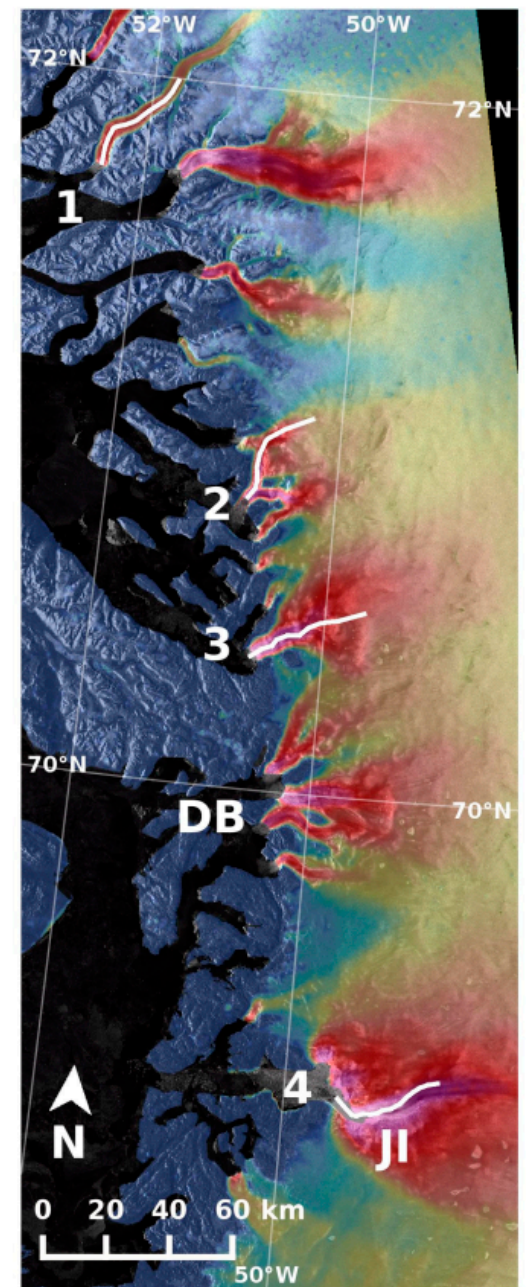

(a)

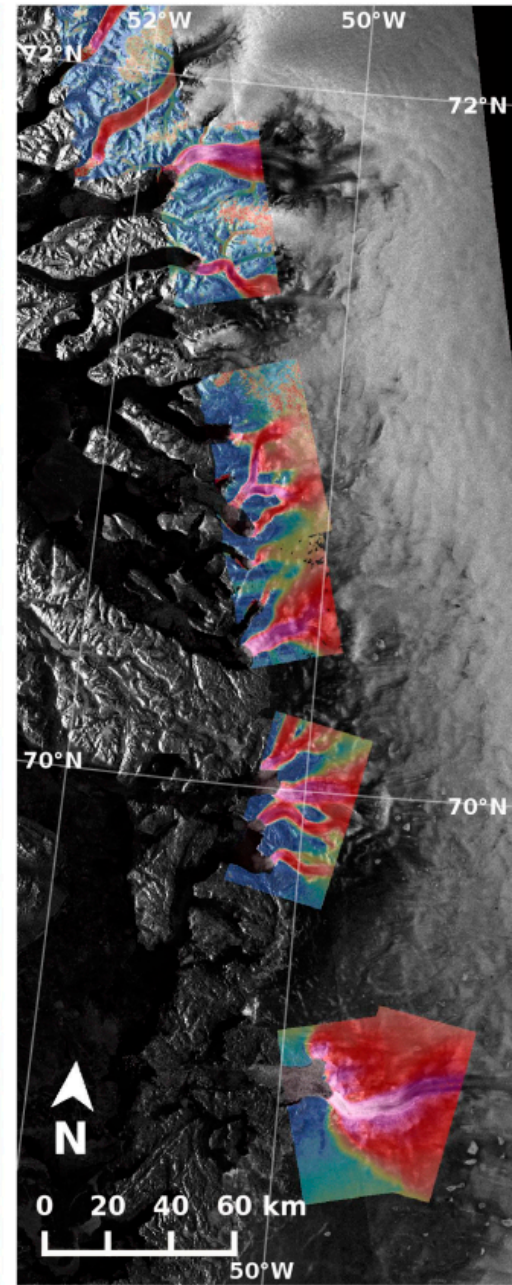

(b)

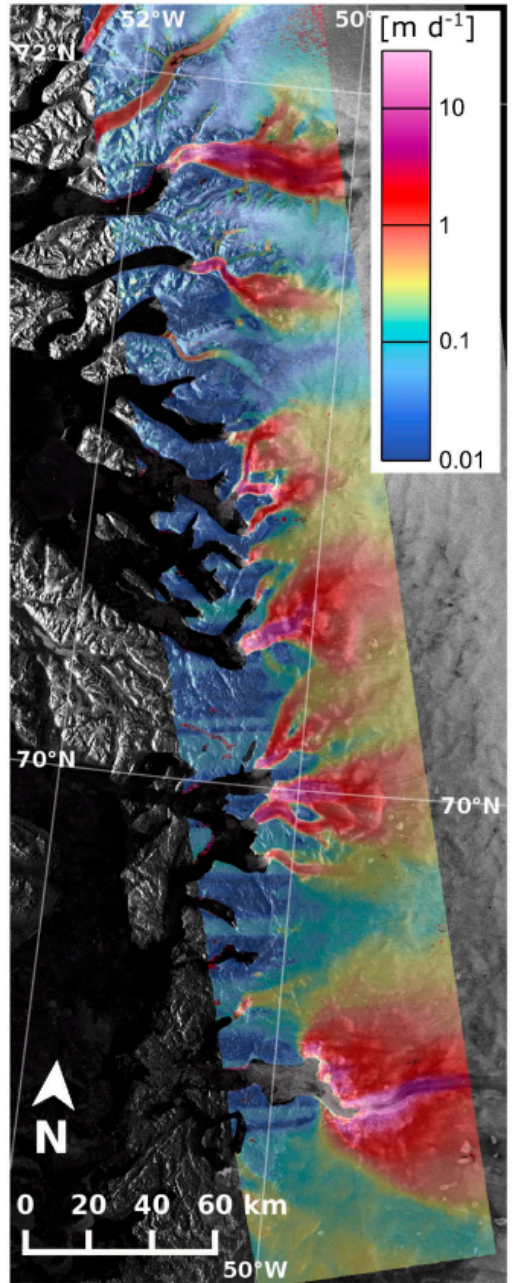

(c)

Figure 2. Maps of ice velocity on outlet glaciers of the Greenland west coast, derived from SAR data of (a) Sentinel-1, 3-15 January 2015; (b) TerraSAR-X, 11 days repeat pass from different epochs in December 2014 and February 2015; and (c) PALSAR, 20 November 2009-5 January 2010. DB-northern Disco Bugt; JI-Jakobshavn Isbrae. White lines show profiles of Figure 6: 1-Umiammakku Isbrae, 2-Sermeq Silarleq, 3-Store Gletsjer, 4-Jakboshavn Isbrae. 


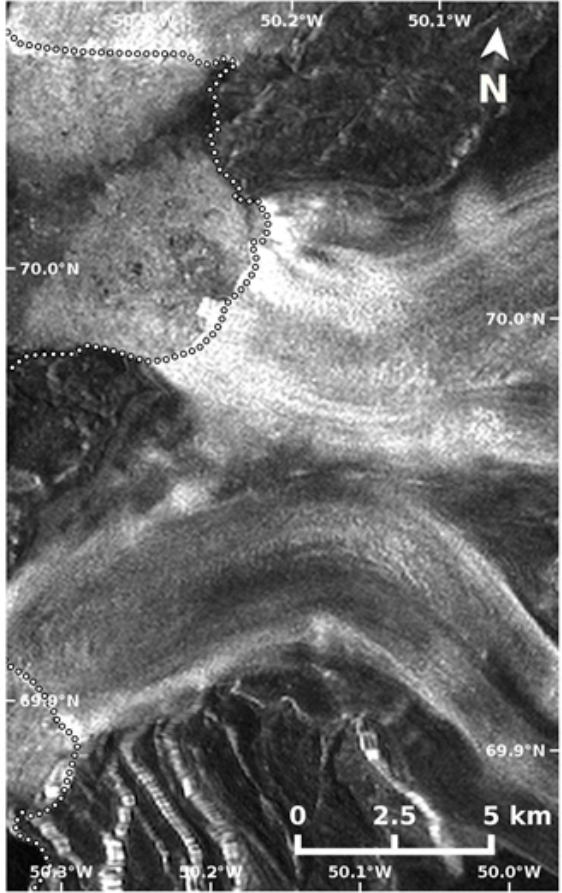

(a)

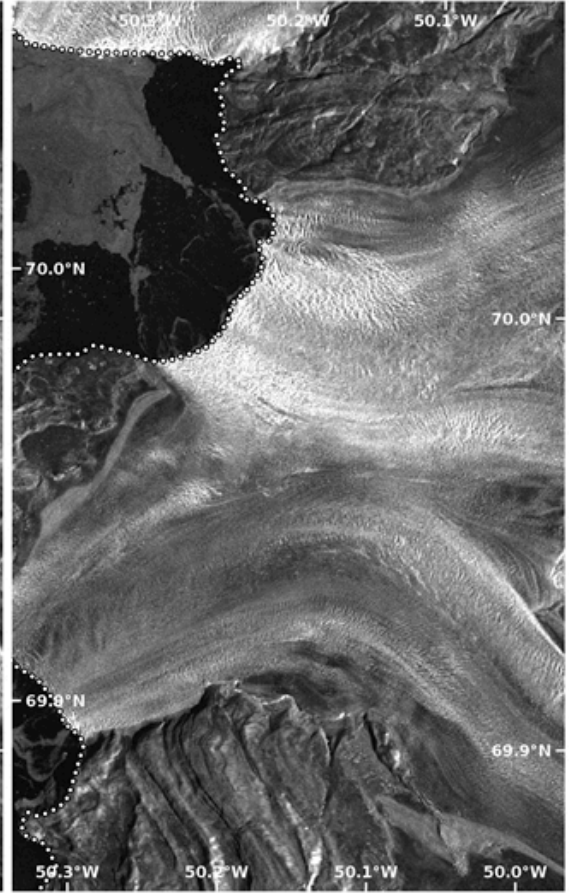

(b)

Figure 3. SAR amplitude image of the glaciers Sermeq Kujalleq and Kangilernata Sermia, draining into the northern Disko Bugt, geocoded using the GIMP DEM at $30 \mathrm{~m}$ grid. (a) Section of Sentinel-1 IW image, 3 January 2015. (b) Section of TerraSAR-X image, 20 December 2014. Dotted line: Coastline on 20 December 2014.

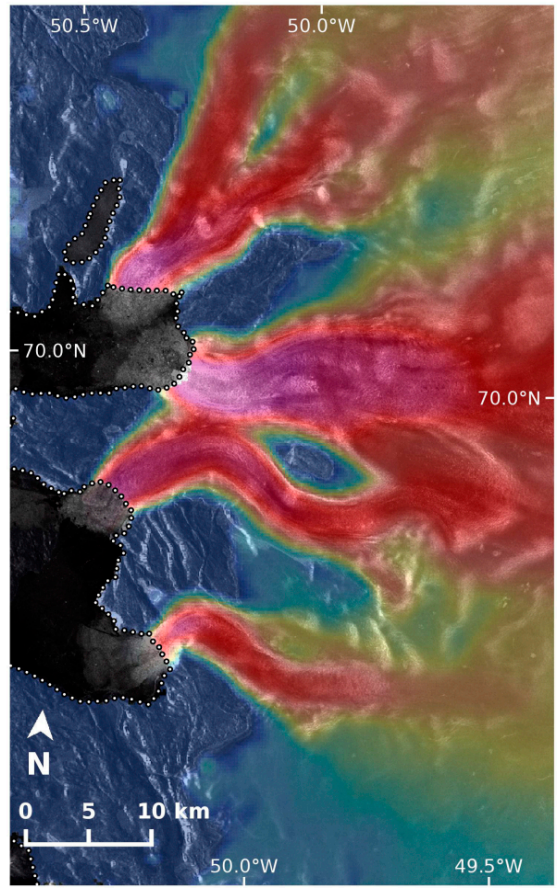

(a)

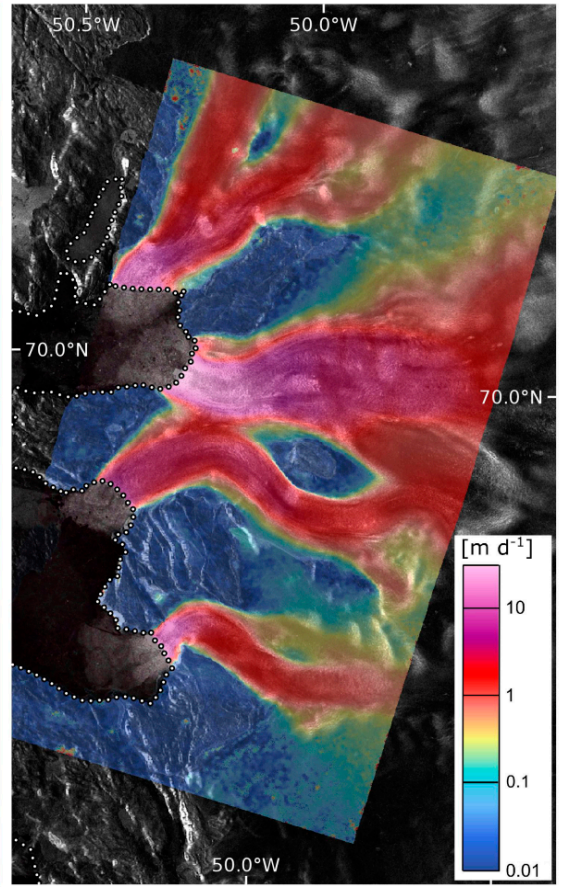

(b)

Figure 4. Maps of ice velocity on outlet glaciers to the northern Disko Bugt (DB in Figure 2) derived from (a) SAR data of Sentinel-1, 3 to 15 January 2015. (b) TerraSAR-X, 9 to 20 December 2014. Dotted line: Coastline. 


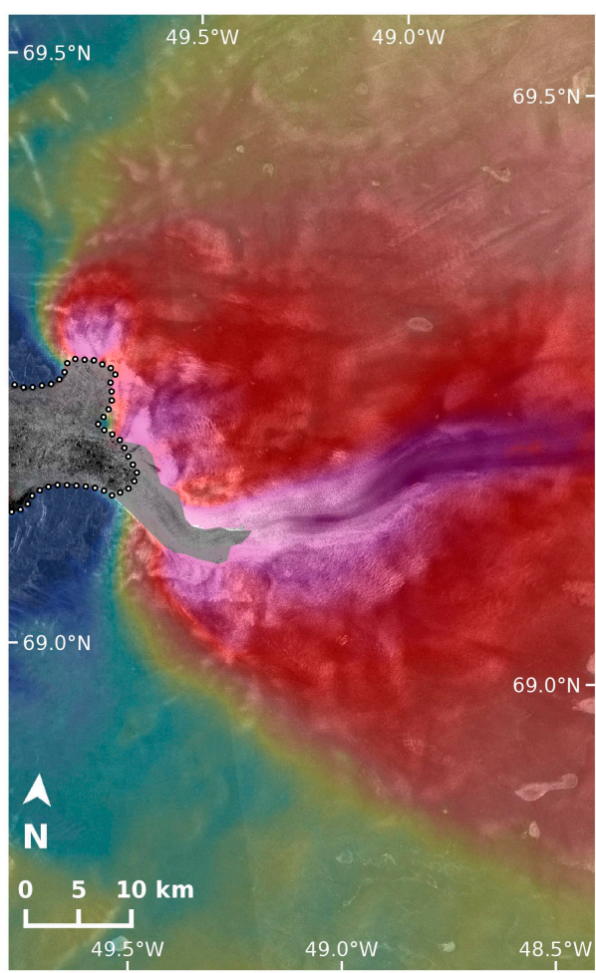

(a)

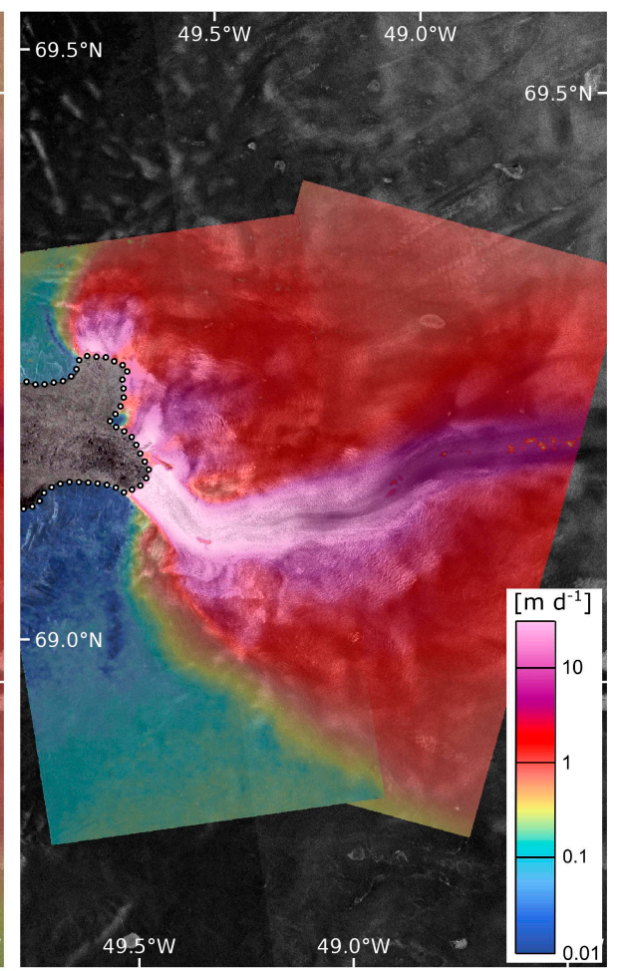

(b)

Figure 5. Maps of ice velocity on Jakobshavn Isbrae (JI in Figure 2) derived from (a) SAR data of Sentinel-1, 3 to 15 January 2015. (b) TerraSAR-X, 8 to 19 February 2015. Dotted line: Coastline. Grey area: no velocity data obtained from S1.

Table 3. Specifications for ice motion analysis along central flowlines of outlet glaciers in Greenland west coast (shown in Figure 6). Location of velocity profiles in Figure 2. Coordinates specified for center point of calving fronts in January 2015. Time span refers to epoch for velocity retrievals.

\begin{tabular}{|c|c|c|c|c|}
\hline Glacier & $\begin{array}{c}\text { Front } \\
\text { Coordinates }\end{array}$ & Time Span S1 & Time Span TerraSAR-X & Time Span PALSAR \\
\hline Umiammakku & $71.727^{\circ} \mathrm{N}$ & 22. December 2014- & 12 December 2014- & 15 September-31 October 2008 \\
\hline Isbrae & $52.397^{\circ} \mathrm{W}$ & 3 January 2015 & 1 January 2015 & 20 November 2009-5 January 2010 \\
\hline $\begin{array}{l}\text { Sermeq } \\
\text { Silarleq }\end{array}$ & $\begin{array}{l}70.830^{\circ} \mathrm{N} \\
50.760^{\circ} \mathrm{W}\end{array}$ & $\begin{array}{c}0 \text { to } 15 \mathrm{~km} \\
22 \text { December } 2014- \\
\text { 3 January } 2015 \\
\text { from } 15 \text { to } 35 \mathrm{~km} \text { : } \\
\text { 3-15 January } 2015\end{array}$ & 16-27 December 2014 & $\begin{array}{c}15 \text { September-31 October } 2008 \\
20 \text { November 2009-5 January } 2010\end{array}$ \\
\hline Store Gletsjer & $\begin{array}{l}70.378^{\circ} \mathrm{N} \\
50.611^{\circ} \mathrm{W} \\
\end{array}$ & 3-15 January 2015 & 3-14 February 2015 & $\begin{array}{c}15 \text { September-31 October } 2008 \\
20 \text { November 2009-5 January } 2010\end{array}$ \\
\hline $\begin{array}{c}\text { Jakboshavn } \\
\text { Isbrae }\end{array}$ & $\begin{array}{l}69.147^{\circ} \mathrm{N} \\
49.571^{\circ} \mathrm{W}\end{array}$ & 3-15 January 2015 & 8-19 February 2015 & $\begin{array}{c}15 \text { September-31 October } 2008 \\
20 \text { November 2009-5 January } 2010\end{array}$ \\
\hline
\end{tabular}



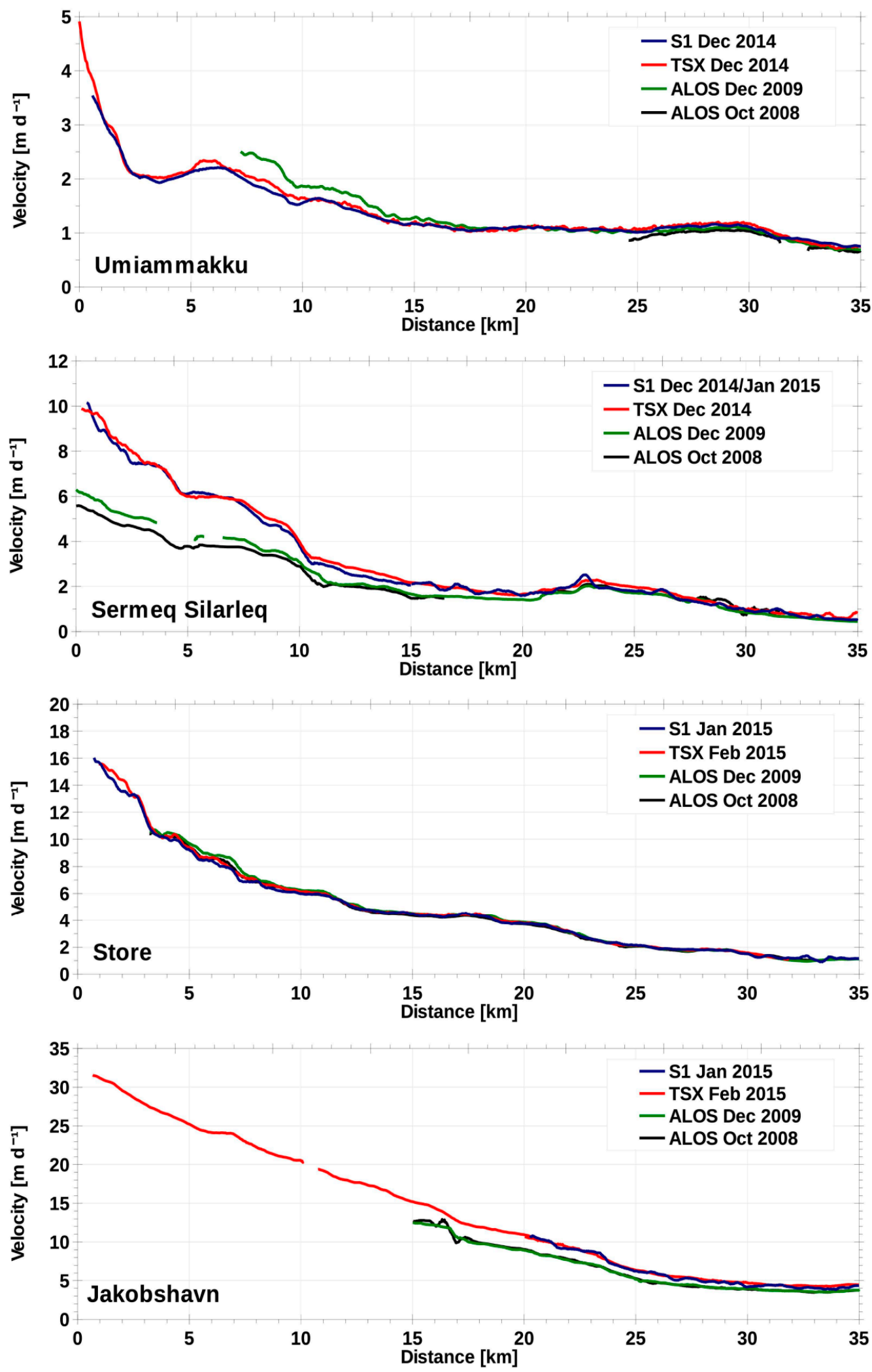

Figure 6. Maps of ice velocity along central flowlines for Umiammakku Isbræ, Sermeq Silarleq, Store Gletsjer, and Jakobshavn Isbræ. Distance upstream of ice front in January 2015. Location of profiles in Figure 2. 


\subsection{Error Estimate}

There are three main sources of error for retrieval of ice motion by means of offset tracking:

1. The error introduced during the matching procedure used to determine the offsets of the image templates. This error is related to the degree of correlation between the templates in the different images. It depends on the co-registration of the image pairs, the template size, and on the quality of amplitude features and/or stability of speckle used for tracking.

2. Ionospheric disturbances due to fluctuations in ionospheric electron density that are causing phase gradients resulting in azimuth shifts [29]. These are clearly evident as streaks in the retrieved velocity, aligned slightly oblique to the LOS direction.

3. Geocoding error. Due to the very precise ephemeris data for S1 the error through transformation from slant range to map projection is primarily caused by height errors in the DEM used for topographic correction.

The impact of ionospheric disturbances varies significantly over time and position. For C-band SAR a range of values is reported in the literature. Joughin et al. [27] explain that ionospheric disturbances near the solar maximum over Greenland may generate noise in the velocity field retrieved from C-band RADARSAT-1 data with magnitudes of up to several tens of $\mathrm{m} \cdot \mathrm{a}^{-1}$. Gray et al. [29] report peak-to-peak modulation in azimuth shift in RADARSAT-1 data of Antarctica of up to $1 \mathrm{~m}$, which corresponds to a displacement of $0.042 \mathrm{~m} \cdot \mathrm{d}^{-1}$. Mouginot et al. [28] explain that ionospheric disturbances cause maximum velocity errors of $\pm 6 \mathrm{~m} \cdot \mathrm{a}^{-1}$ (corresponding to $\pm 0.016 \mathrm{~m} \cdot \mathrm{d}^{-1}$ ) for RADARSAT ice velocity retrievals over Antarctica.

Because of the shorter repeat cycle for S1 versus RADARSAT-1 (12 days versus 24 days), the potential impact of ionosphere-induced noise on the velocity is doubled. In our data set the ionosphere variability appears as distinct streaks in several velocity maps derived from single S1 image pairs over northern Greenland with peak values equivalent to displacements of $0.25 \mathrm{~m} \cdot \mathrm{d}^{-1}$. For a large area $(>200,000$ pixels) in the central section of northern Greenland with low velocities, we obtain a standard error of $0.08 \mathrm{~m} \cdot \mathrm{d}^{-1}$ due to ionospheric disturbance. By averaging over multiple acquisitions, the error is reduced to $0.02 \mathrm{~m} \cdot \mathrm{d}^{-1}$. This confirms that efficient reduction of ionospheric noise is achieved through averaging of retrieval from multiple image pairs as reported by $[27,28]$.

The geocoding accuracy of the S1 ice velocity maps is related to the accuracy of the GIMP DEM used for topographic correction. The DEM has a reported ice-sheet wide root-mean-squared height error, relative to ICESat, of $\pm 10 \mathrm{~m}$, ranging from close to $\pm 1 \mathrm{~m}$ over the main part of the ice sheet to $\pm 30 \mathrm{~m}$ in areas of high relief [23]. The geocoding of the $2 \mathrm{D}$ velocity vector retrieved in radar geometry is performed for each displacement value independently, so that DEM errors do not propagate. The DEM has a nominal date of 2007. Since that date major changes in surface elevation happened on the termini of outlet glaciers due to dynamic thinning. For estimating the possible impact of changes of surface topography due to dynamic thinning on outlet glaciers, we selected as example Jakobshavn Isbrae. The rate of surface lowering between 2007 and 2010 was $15 \mathrm{~m} \cdot \mathrm{a}^{-1}$ near the front and $8 \mathrm{~m} \cdot \mathrm{a}^{-1} 20 \mathrm{~km}$ upstream [32]. This rate of surface lowering over a period of eight years results in a change of the surface slope of 0.16 degrees, resulting in a bias of $0.5 \%$ in the magnitude of surface velocity. The lower terminus of Jakobshavn Glacier represents an extreme case in terms of dynamic thickness change [33]. 
For estimating the uncertainty of S1 velocities, we compare S1 velocity products with ice velocity maps retrieved from TerraSAR-X data (Figure 2). The comparisons are performed with TerraSAR-X velocity maps retrieved from single SAR repeat pass pairs. For S1 velocity data acquired from single image pairs and velocity data from the velocity mosaic are used. Because of possible temporal variations in velocity the lower sections of glacier tongues are not used for the comparison. We computed the root mean square error (RMSE) of velocity magnitude between TerraSAR-X and S1 for 28 areas with mean velocities ranging from $1 \mathrm{~m} \cdot \mathrm{d}^{-1}$ to $10 \mathrm{~m} \cdot \mathrm{d}^{-1}$. The RMSE for this data set corresponds to $7.4 \%$ of the mean velocity for S1 velocities from a single image pair and to $4.8 \%$ for the merged S1 velocity map. These values include the total uncertainties both for the S1 velocities and the TerraSAR-X velocities. Ahlstrøm et al. [34] compare velocity maps from TerraSAR-X/TanDEM-X data with in-situ velocity records measured with GPS receivers on several Greenland glaciers. For measurements over 11-day intervals they report a mean difference of $1.5 \%$ between TerraSAR-X/TanDEM-X and GPS velocities. Assuming similar uncertainty for our TerraSAR-X retrievals, the RMSE can primarily be attributed to uncertainty in the $\mathrm{S} 1$ velocity data. The uncertainty for slow moving areas was calculated by deriving the RMSE for 12 areas with mean velocities between $0.1 \mathrm{~m} \cdot \mathrm{d}^{-1}$ to $0.5 \mathrm{~m} \cdot \mathrm{d}^{-1}$. For S1 velocities retrieved from a single image pair the RMSE is $0.068 \mathrm{~m} \cdot \mathrm{d}^{-1}$, and for the merged $\mathrm{S} 1$ ice velocity map the RMSE is $0.047 \mathrm{~m} \cdot \mathrm{d}^{-1}$. The higher relative error at slow velocities is due to the impact of ionospheric noise in the total error budget.

\section{Discussion}

Ice sheet monitoring in support of climate change studies is one of the main application domains for the Sentinel-1 mission over land [4]. The high duty cycle of up to $25 \mathrm{~min}$ per orbit, the wide coverage of the IW mode as nominal operation mode over land, and the long-term commitment for operation of the mission opens up unique capabilities for building up consistent, long-term data archives on ice sheet parameters. The mission operation is based on stable and predefined observation scenarios and systematic production schemes. The baseline observation scenario over ice sheets applies the IW mode with $250 \mathrm{~km}$ swath width and $5 \mathrm{~m} \times 20 \mathrm{~m}$ spatial resolution. We investigated the feasibility and performance of Sentinel-1 for mapping and monitoring ice sheet motion, based on the first comprehensive ice sheet data set acquired by this satellite. In this section, we discuss properties of the Sentinel-1 ice velocity product of Greenland with reference to ice motion maps from previous years, based on other SAR sensors.

Rignot and Mouginot [13] produced a comprehensive digital mosaic of ice motion in Greenland for the IPY assembled from SAR data of ALOS PALSAR, RADARSAT-1, and Envisat ASAR, applying a speckle tracking algorithm. Most of the data were acquired in fall 2009, with some additional tracks from fall 2007 and 2008. The IPY velocity map covers $99 \%$ of the ice sheet area. The PALSAR motion retrievals represent the main contribution to the composite ice motion map because of the good temporal coherence of the L-band data (wavelength $24 \mathrm{~cm}$ ) in spite of the long repeat cycle of 46 days. The C-band signal (wavelength $5.6 \mathrm{~cm}$ ) is more sensitive to temporal decorrelation caused by meteorological events. For this reason the RADARSAT-1 (repeat cycle of 24 days) and the ASAR (repeat cycle 35 days) ice motion data show large gaps, in particular in the interior part of Greenland [13]. The RADARSAT-1 ice velocity maps of individual winters of Joughin et al. [27] show large gaps, in particular in the central, 
southeast and south sections of the ice sheet. Whereas L-band SAR offers better performance in terms of coherence, ionospheric perturbations are smaller at C-band [13,28].

The S1 ice velocity map of Greenland (Figure 1), based on SAR data of winter 2015, shows some gaps in the southeast sections as the RADARSAT-1 ice motion maps of individual winters [27]. However, the S1 velocity shows overall a more extended coverage over the ice sheet. This can probably be attributed to the shorter repeat cycle of S1 (12 days). Further improvements in coverage can be expected after full deployment of the S1 mission when two satellites will fly in coordinated orbits providing six-day repeat coverage, which helps to reduce temporal decorrelation [5].

For velocity retrievals on outlet glaciers the temporal decorrelation is of less concern than in the interior of the ice sheet, because in ablation areas template matching uses mainly conservative amplitude features (crevasses, flowlines, drainage patterns) rather than speckle patterns. A critical issue is the ability to obtain reliable correlation peaks on fast-moving glaciers. The spatial resolution of the sensor and the length of the repeat observation cycle are the main parameters determining the feasibility for resolving velocity fields in zones of strong shear and deformation.

The enlarged sections of the ice flow map in Figures 4 and 5 and the velocity profiles in Figure 6 help to illuminate this issue. The $\mathrm{S} 1$ offset tracking analysis provides complete motion fields for the glaciers draining into the northern Disko Bugt and for the fast-flowing Store Gletsjer, which has a frontal velocity of $16 \mathrm{~m} \cdot \mathrm{d}^{-1}$. On Jakobshavn Isbræ the TerraSAR-X analysis of February 2015 yields a frontal velocity of $32 \mathrm{~m} \cdot \mathrm{d}^{-1}$ (Figure 6), similar to velocities observed in February 2013 and February 2014 [30]. The S1 analysis delivers continuous velocity data upstream of a point $20 \mathrm{~km}$ inland where the velocity is $11 \mathrm{~m} \cdot \mathrm{d}^{-1}$. With PALSAR we obtain velocities upstream of $15 \mathrm{~km}$. The impact of sensor resolution for retrieving ice velocities on this fast flowing ice stream with strong shear is obvious. The TerraSAR-X high-resolution Strip Map images, acquired with 11-day repeat, deliver high quality velocity over the entire terminus. For PALSAR the spatial resolution in LOS is slightly lower than for S1 IW mode data, but the resolution in azimuth is four times higher (Table 1). In spite of the longer repeat cycle, PALSAR provides velocities slightly further downstream than $\mathrm{S} 1$. One reason for this could be the unfavorable orientation of the main velocity gradient with respect to the S1 track, which is aligned approximately perpendicular to the azimuth direction in the S1 images. Because of the lower spatial resolution in azimuth, the IW mode data are less sensitive to velocity gradients in azimuth than across track.

The S1 Strip Map mode data, with nominal spatial resolution of $5 \mathrm{~m} \times 5 \mathrm{~m}$, would offer the possibility for closing gaps on fast flowing glaciers. However, the S1 operation strategy allows only in exceptional cases (e.g., emergency requests) for Strip Map mode acquisitions to supersede the systematic acquisition plan [5]. On the other hand, the availability of six-day repeat pass data after the launch of Sentinel-1B will offer the opportunity to largely reduce the (rather limited) gaps in velocity coverage over fast flowing glaciers with IW mode data. The shorter repeat observations will also be of interest for interferometric retrievals of ice motion and deformation with S1 IW mode data, in particular for slowly moving ice.

\section{Conclusions}

The Sentinel satellite missions, developed and operated by ESA for the European Copernicus Programme under the leadership of the European Commission, provide the science community with 
powerful and long-term observation capabilities for key variables of the Earth system [2]. Each Sentinel mission is based on a constellation of two identical satellites. The Sentinels, together with the Earth Explorer missions that are addressing specific scientific questions of high urgency, are representing the core of ESA's Living Planet Programme [35].

In addition to surface motion, the S1 SAR will provide regular repeat observations of other key ice sheet variables, including ice shelf margins, calving fronts of outlet glaciers, extent of surface melt areas, and surface drainage features. The capabilities of the Copernicus space component for ice sheet observations will be complemented by the Sentinel-2 and Sentinel-3 missions [3]. Sentinel-2 is a polar-orbiting, multispectral high-resolution imaging mission at visible and near infrared wavelengths [36]. The first Sentinel-2 satellite was launched on 23 June 2015. Ice sheet applications will include the mapping of outlet glaciers, ice boundaries, surface features and albedo, complementary to the high-resolution radar observations of S1. The Sentinel-3 mission combines optical medium-resolution observations by an imaging spectrometer and a dual-view multispectral radiometer, and altimetry measurements by a dual frequency synthetic aperture radar altimeter (SRAL) [37]. Main products of the optical sensors over the ice sheets will be spectral surface albedo and surface temperature. SRAL, including an along-track SAR capability of CryoSat-2 heritage, will observe surface topography and surface elevation change with increased measurement accuracy and along track resolution when compared to conventional altimetry products.

In this paper, we highlight the capability of the Sentinel-1 mission for spatially detailed, ice-sheet wide monitoring of surface motion. Sentinel-1 with its IW mode delivers high resolution SAR data at wider coverage and shorter repeat cycle compared to previous SAR missions. Comprehensive mapping of ice motion at regular repeat intervals, as demonstrated with the first S1 ice velocity map of Greenland, will provide an important new database for understanding ice-sheet variability and the processes linking ice dynamics and climate forcing. The long-term S1 acquisition strategy for Greenland plans for two campaigns per year with full coverage of Greenland, comprising about 30 tracks in IW mode. The current plan comprises three consecutive repeat acquisitions, allowing the formation of two 12-day image pairs. The extension to a fourth repeat acquisition is advisable, in order to improve the likelihood of good coherence for ice velocity retrievals in regions of frequent snowfall. In addition to regular ice-sheet-wide acquisitions, it is planned to continuously monitor Greenland's ice margins with six tracks within every repeat cycle, providing 12-day temporal sampling with Sentinel-1A, shortened to six-day repeat once Sentinel-1B will be operational. This data set will be an excellent basis for observations of short-term variability and long-term trends in ice flow and mass export of Greenland's outlet glaciers.

\section{Acknowledgments}

The work was supported by the European Space Agency, Ice Sheet CCI project (ESA Contract No. 40000104815/11/I-NB), and by the Austrian Research Promotion Agency, FFG, Austrian Space Application Programme (Contract Nr. 844386). The TerraSAR-X data were made available by DLR through the project HYD0096, the ALOS PALSAR data through the ESA ALDEN AOALO 3741 project.

\section{Author Contributions}

Thomas Nagler initiated and led the project. Thomas Nagler and Helmut Rott performed the scientific analysis and prepared the manuscript. Markus Hetzenecker and Jan Wuite developed the processing 
tools and were in charge of data processing. Pierre Potin was responsible for data acquisition. All authors contributed to editing the manuscript.

\section{Conflicts of Interest}

The authors declare no conflict of interest.

\section{References}

1. Aschbacher, J.; Milagro-Peréz, M.P. The European Earth monitoring (GMES) programme: Status and perspectives. Remote Sens. Environ. 2012, 120, 3-8.

2. Berger, M.; Moreno, J.; Johannessen, J.; Levelt, P.; Hanssen, R. ESA's sentinel missions in support of earth system science. Remote Sens. Environ. 2012, 120, 84-90.

3. Malenovský, Z.; Rott, H.; Cihlar, J.; Schaepman, M.E.; García-Santos, G.; Fernandes, R.; Berger, M. Sentinels for science: Potential of Sentinel-1, -2, and -3 missions for scientific observations of ocean, cryosphere, and land. Remote Sens. Environ. 2012, 120, 91-101.

4. Potin, P.; Rosich, B.; Roeder, J.; Bargellini, P. Sentinel-1 mission operations concept. In Proceedings of the IEEE IGARSS, Québec, QC, Canada, 13-18 July 2014; pp. 1465-1468.

5. Torres, R.; Snoeij, P.; Geudtner, D.; Bibby, D.; Davidson, M.; Attema, E.; Potin, P.; Rommen, B.; Floury, N.; Brown, M.; et al. GMES Sentinel-1 mission. Remote Sens. Environ. 2012, 120, 9-24.

6. Geudtner, D.; Torres, R.; Snoeij, P.; Davidson, M.; Rommen, B. Sentinel-1 system capabilities and applications. In Proceedings of the IEEE IGARSS, Québec City, QC, Canada, 13-18 July 2014; pp. 1457-1460.

7. Howat, I.M.; Joughin, I.R.; Scambos, T.A. Rapid changes in ice discharge from Greenland outlet glaciers. Science 2007, 315, 1559-1561.

8. Joughin, I.; Das, S.B.; King, M.A.; Smith, B.E.; Howat, I.M.; Moon, T. Seasonal speed-up along the western flank of the Greenland Ice Sheet. Science 2008, 320, 781-783.

9. Van de Wal, R.S.W.; Boot, W.; van den Broeke, M.R.; Smeets, C.J.P.P.; Reijmer, C.H.; Donker, J.J.A.; Oerlemans, J. Large and rapid melt-induced velocity changes in the ablation zone of the Greenland ice sheet. Science 2008, 321, 111-113.

10. Wuite, J.; Rott, H.; Hetzenecker, M.; Floricioiu, D.; de Rydt, J.; Gudmundsson, H.G.; Nagler, T.; Kern, M. Evolution of surface velocities and ice discharge of Larsen B outlet glaciers from 1995 to 2013. Cryosphere 2015, 9, 957-969.

11. Moon, T.; Joughin, I.; Smith, B.; Howat, I. 21st-century evolution of Greenland outlet glacier velocities. Science 2012, 336, 576-578.

12. Rignot, E.; Mouginot, J.; Scheuchl, B. Ice flow of the Antarctic Ice Sheet. Science 2011, 333, 1427-1430.

13. Rignot, E.; Mouginot, J. Ice flow in Greenland for the international polar year 2008-2009. Geophys. Res. Lett. 2012, 39, L11501.

14. De Zan, F.; Monti Guarnieri, A. TOPSAR: Terrain observation by progressive scans. IEEE Trans. Geosci. Remote Sens. 2006, 44, 2352-2360. 
15. Rodriguez-Cassola, M.; Prats-Iraola, P.; de Zan, F.; Scheiber, R.; Reigber, A.; Geudtner, D.; Moreira, A. Doppler-related distortions in TOPS SAR images. IEEE Trans. Geosci. Remote Sens. 2015, 53, 25-35.

16. Thain, C.; Herbert, C.; Lim, P. Sentinel-1 Product Specification; MDA Document Number: SEN-RS-52-7441, Reference S1-RS-MDA-52-7441; ESA: Frascati, Italy, 2014.

17. Holzner, J.; Bamler, R. Burst-mode and ScanSAR interferometry. IEEE Trans. Geosci. Remote Sens. 2002, 40, 1917-1934.

18. Breit, H.; Fritz, T.; Balss, U.; Lachaise, M.; Niedermeier, A.; Vonavka, M. TerraSAR-X SAR processing and products. IEEE Trans. Geosci. Remote Sens. 2010, 48, 717-727.

19. Shimada, M.; Isoguchi, O.; Tadono, T.; Isono, K. PALSAR radiometric and geometric calibration. IEEE Trans. Geosci. Remote Sens. 2009, 47, 3915-3932.

20. Strozzi, T.; Luckman, A.; Murray, T.; Wegmüller, U.; Werner, C. Glacier motion estimation using SAR offset-tracking procedures. IEEE Trans. Geosci. Remote Sens. 2002, 40, 2384-2391.

21. Rott, H. Advances in interferometric synthetic aperture radar (InSAR) in earth system science. Prog. Phys. Geogr. 2009, 33, 769-791.

22. Bamler, R.; Hartl, P. Synthetic aperture radar interferometry. Inverse Probl. 1998, 14, R1-R54.

23. Howat, I.M.; Negrete, A.; Smith, B.E. The Greenland Ice Mapping Project (GIMP) land classification and surface elevation datasets. Cryosphere 2014, 8, 1509-1518.

24. Sansosti, E.; Berardino, P.; Manunta, M.; Serafino, F.; Fornaro, G. Geometrical SAR image registration. IEEE Trans. Geosci. Remote Sens. 2006, 44, 2861-2870.

25. Prats-Iraola, P.; Scheiber, R.; Marotti, L.; Wollstadt, S.; Reigber, A. TOPS interferometry with TerraSAR-X. IEEE Trans. Geosci. Remote Sens. 2012, 50, 3179-3188.

26. Miranda, N.; Palumbo, G. Sentinel-1 Instrument and Product Performance Status. Available online: http://seom.esa.int/fringe2015/files/presentation359.pdf (accessed on 11 May 2015).

27. Joughin, I.; Smith, B.E.; Howat, I.M.; Scambos, T.; Moon, T. Greenland flow variability from ice-sheet-wide velocity mapping. J. Glaciol. 2010, 56, 415-430.

28. Mouginot, J.; Scheuchl, B.; Rignot, E. Mapping of ice motion in Antarctica using synthetic-aperture radar data. Remote Sens. 2012, 4, 2753-2767.

29. Gray, A.L.; Mattar, K.E.; Sofko, G. Influence of ionospheric electron density fluctuations on satellite radar interferometry. Geophys. Res. Lett. 2000, 27, 1451-1454.

30. Joughin, I.; Smith, B.E.; Shean, D.E.; Floricioiu, D. Brief communication: Further summer speedup of Jakobshavn Isbræ. Cryosphere 2014, 8, 209-214, doi:10.5194/tc-8-209-2014.

31. Moon, T.; Joughin, I.; Smith, B.; van den Broeke, M.R.; van de Berg, W.J.; Noël, B.; Usher, M. Distinct patterns of seasonal Greenland glacier velocity. Geophys. Res. Lett. 2014, 41, 7209-7216.

32. Joughin, I.; Smith, B.E.; Howat, I.M.; Floricioiu, D.; Alley, R.B.; Truffer, M.; Fahnestock, M. Seasonal to decadal scale variations in the surface velocity of Jakobshavn Isbrae, Greenland: Observation and model-based analysis. J. Geophys. Res. 2012, 117, doi:10.1029/2011JF002110.

33. Csatho, B.M.; Schenk, A.F.; van der Veen, C.J.; Babonis, G.; Duncan, K.; Rezvanbehbahani, S.; van den Broeke, M.R.; Simonsen, S.B.N.; Nagarajan, S.; van Angelen, J.H. Laser altimetry reveals complex pattern of Greenland Ice Sheet dynamics. Proc. Natl. Acad. Sci. USA 2014, 111, $18478-18483$. 
34. Ahlstrøm, A.P.; Andersen, S.B.; Andersen, M.L.; Machguth, H.; Nick, F.M.; Joughin, I.; Reijmer, C.H.; van de Wal, R.; Boncori, J.P.; Box, J.E. Seasonal velocities of eight major marine-terminating outlet glaciers of the Greenland ice sheet from continuous in situ GPS instrument. Earth Syst. Sci. Data 2013, 5, doi:10.5194/essd-5-277-2013.

35. ESA. The Changing Earth-New Scientific Challenges for ESA's Living Planet Programme; ESA SP-1304; ESA: Frascati, Italy, 2006. Available online: http://www.esa.int/esaMI/ESA_ Publications/SEMAJUB474F_0.html (accessed on 17 July 2015).

36. Drusch, M.; Del Bello, U.; Carlier, S.; Colin, O.; Fernandez, V.; Gascon, F.; Hoersch, B.; Isola, C.; Laberinti, P.; Martimort, P.; et al. Sentinel-2: ESA's optical high-resolution mission for GMES operational services. Remote Sens. Environ. 2012, 120, 25-36.

37. Donlon, C.; Berruti, B.; Buongiorno, A.; Ferreira, M.-H.; Féménias, P.; Frerick, J.; Goryl, P.; Klein, U.; Laur, H.; Mavrocordatos, C.; et al. The Global Monitoring for Environment and Security (GMES) Sentinel-3 mission. Remote Sens. Environ. 2012, 120, 37-57.

(C) 2015 by the authors; licensee MDPI, Basel, Switzerland. This article is an open access article distributed under the terms and conditions of the Creative Commons Attribution license (http://creativecommons.org/licenses/by/4.0/). 